Wh

W.

2. In

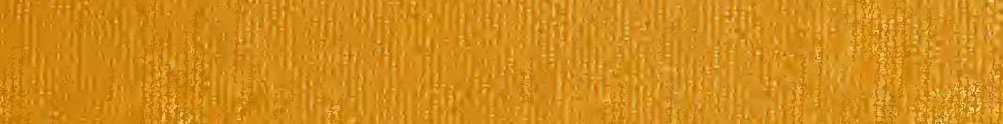

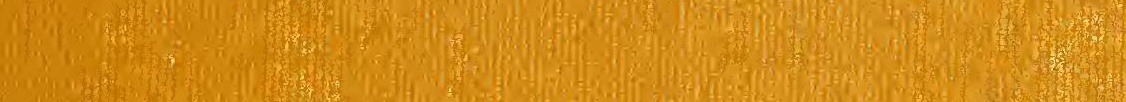

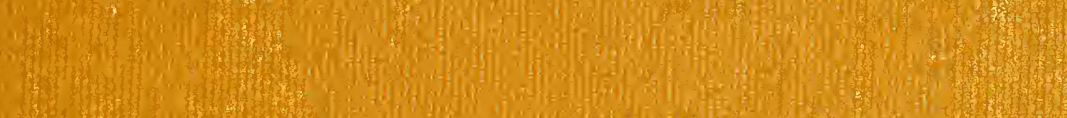
(20)

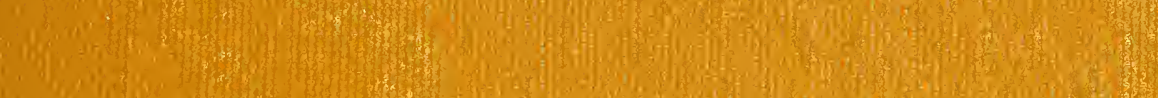

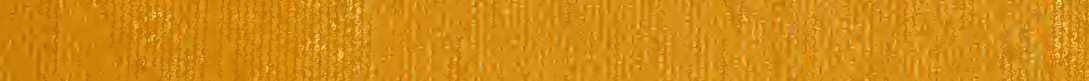
(1)

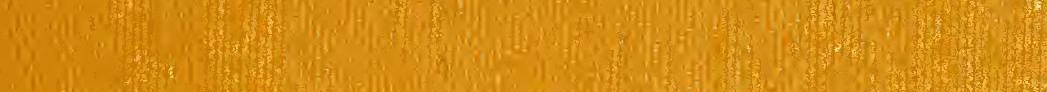

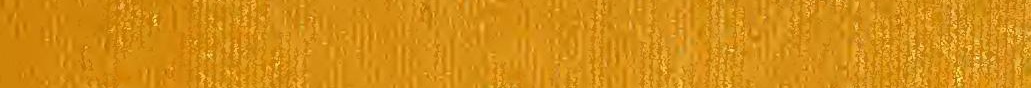

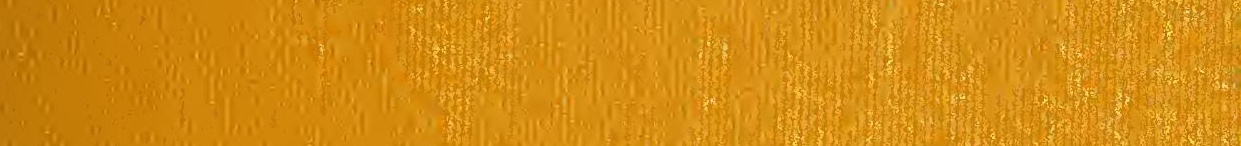

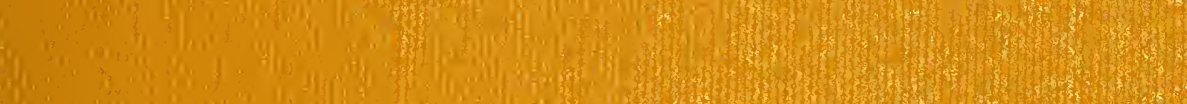
(1) M.

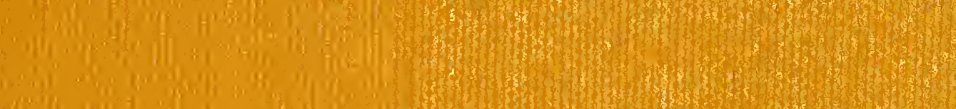
Sy (4. Whan

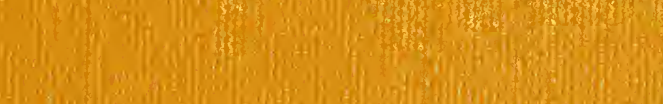
(1) (4) (1) $\therefore$ and

(1)

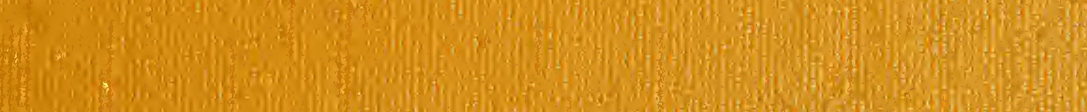

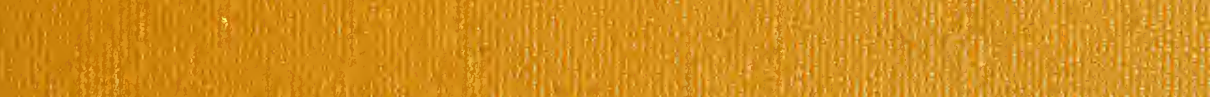
(x) The 


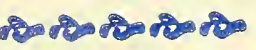

PLEASE HANDLE WITH CARE

University of Connecticut Libraries
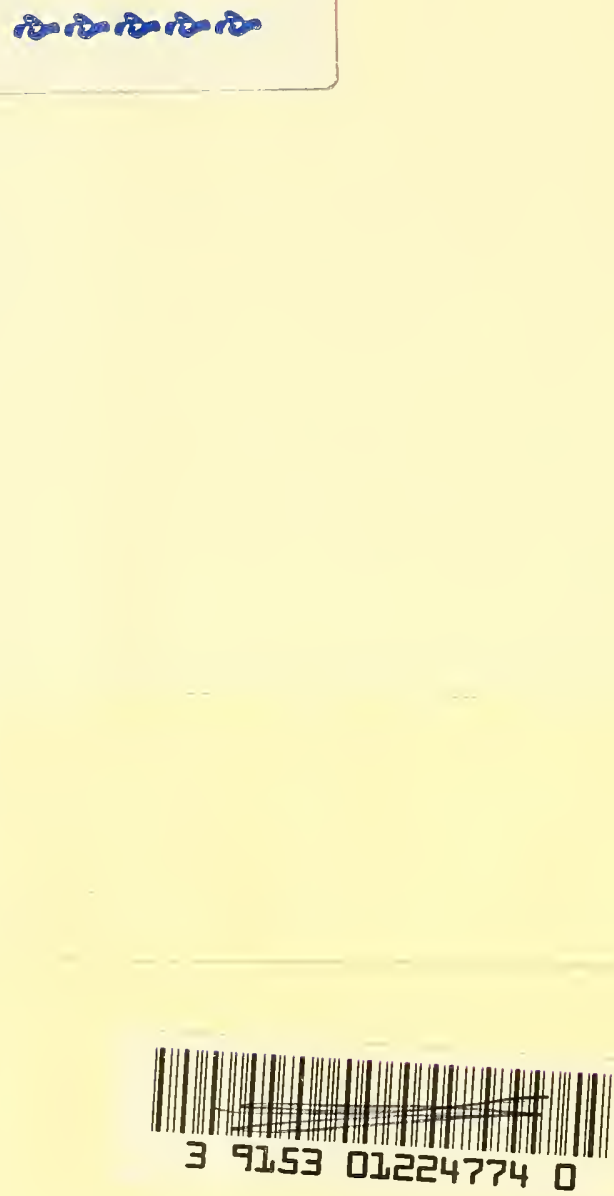

Digitized by the Internet Archive in 2011 with funding from LYRASIS members and Sloan Foundation 
Bulletin 413

July, 1938

\section{Red Pine}

in

\section{Connecticut Forest Plantations}

\section{PART I. VOLUME TABLES \\ FOR RED PINE}

PINUS RESINOSA, SOLANDER

HENRY W. HICOCK AND RAYMOND KIENHOLZ

\section{UTmmentiont}

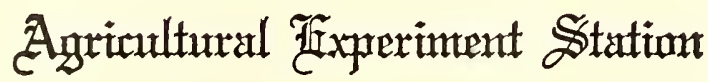

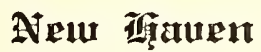





\title{
Red Pine in Connecticut Forest Plantations
}

\author{
Henry W. Hicock ${ }^{1}$ and Raymond Kienholz 2
}

\section{PREFACE}

This is the first of a series of reports on Red Pine, Pinus resinosa Solander, in forest plantations. Red pine has been used extensively for artificial forest regeneration in Connecticut and, up to the present, in excess of 15,000 acres have been planted with this species in the State. Much of this is in pure stands.

Red Pine is native to northern New England but there is some question as to whether or not its natural range extends into Connecticut. The species is handled very easily in the nursery and survival after planting in the field is usually excellent. Grow th on most sites is rapid both in height and diameter. Since this tree has been used either wholly outside of or just within the southern limits of its range and under quite artificial conditions, it became apparent more than a decade ago that the problems involved in management of these planted stands would be quite different from those for natural stands.

In order to secure information which would be useful in advising owners in the proper handling of their plantations, the Connecticut Agricultural Experiment Station began an investigation of these problems in 1929 with a study of growth in relation to site quality. The initial results of this work have been reported ${ }^{3}$. At the same time a method of determining site quality in plantations was also worked out and reported. During the past nine years further investigations have been carried on. Some of this work has been done entirely by members of the Station staff and some in coöperation with other agencies and individuals. A considerable body of data relative to plantation grown red pine has been secured which will be published in several parts under the general title "Red Pine in Connecticut Forest Plantations", with an appropriate subtitle for each part. Part I of the series, including two volume tables for red pine, appears with this introduction. Specific titles for other parts will not be announced at this time. Some of the subjects which will be reported on later are:

The Properties of Red Pine Wood

The Growith of Red Pine

Insect and Fungous Enemies of Red Pine

Survey of Red Pine Plantations in Connectieut

The Yield of Red Pine

1 Associate Forester, Conn. Agr. Exp. Sta., New Haven.

2 Conn. State Forestry Department.

3 The Relation of Forest Composition and Rate of Growth to Certain Soil Characteristics by H. W. Hicock et al. Bul. 330, Conn. Agr. Exp. Sta., New Haven, Connecticut, July, 1931.

4 The Use of Polymorphic Curves in Determining Site Quality in Young Red Pine Plantations by Henry Bull. Journal of Agricultural Research. Vol. 43, pages 1-28, Washington, D.C.; July 1, 1931. 


\section{PART I. THE VOLUME TABLES}

\section{Securing the Field Data}

The field data were taken during the thinning of 22 permanent plots in 1930 and in 1936. The total age of the trees from seed ranged from 16 to 32 years. In all cases the plantations had been established on open fields and the planted trees had not been subjected to competition with other species. The growing space per tree varied from 25 to 40 square feet. Data taken in the field included:

1. Total height of the tree to the nearest tenth of a foot

2. Length of green crown

3. Diameter outside bark to the nearest tenth of an inch and bark thickness at:

a. Stump height, usually 6 inches above ground

b. Three feet above ground

c. Four and one-half feet above ground (breast height)

d. Intervals of one, two......ten tenths of the distance between 4.5 feet above ground and the tip.

\section{Office Computations and Construction of the Tables ${ }^{1}$}

The field data were worked up for plotting on U. S. Forest Service Form 558a, from which, for each tree, two volumes were obtained by planimeter: (a) the total peeled volume of the stem and (b) the volume of the stem, including bark, from a six-inch stump to a two-inch top diameter, outside bark. These volumes were then properly tabulated for use in construction of two volume tables by the alinement chart method as outlined by Reineke and Bruce ${ }^{2}$. The base chart used for both tables was U. S. Forest Service Form 559a. The resulting volume tables are included. Both were based on the same field data and both are given in alinement chart form and in tabular form. Tables 1 and 2 were read from Charts I and II respectively.

The alinement chart is somewhat easier to use for odd diameters and heights because interpolation is unnecessary. If, however, diameters are grouped in whole inch classes and heights by five- or ten-foot classes, volumes are more easily obtained from the table.

A volume table for local use, reading in terms of diameter only, may be made as follows:

1. Obtain sufficient heights in the field to plot a height-on-diameter curve. From this, read heights corresponding to one-inch diameter classes and tabulate.

2. From the chart, read the volumes for the several paired diameterheight values and enter these in the table which will now read as shown on next page:

1 The writers wish to express appreciation to Mr. Robert W. Hess, now Assistant Professor of Forestry at the University of Arkansas, Fayetteville, Arkansas, for his careful and painstaking work in preparation of the data, and to Mr. L. H. Reineke, Silviculturist, Northeastern Forest Experiment Station, New Haven, Connecticut, for help and advice in constructing the alinement charts.

2 An Alinement-Chart Method for Preparing Forest-Tree Volume Tables by L. H. Reineke and Donald Bruce. Tech. Bul. No. 304, U. S. Dept. of Agr., Washington, D.C. 


$\begin{array}{ccc}\text { D.B.H. } & \text { Total } & \text { Volume iN } \\ \text { IN } & \text { Height IN } & \text { Cubic FeEt } \\ \text { Inches } & \text { Feet } & \end{array}$

\begin{tabular}{lrr}
\hline 2.0 & 14.4 & .19 \\
3.0 & 17.7 & .47 \\
4.0 & 20.3 & .91 \\
5.0 & 22.7 & 1.53 \\
etc. & etc. & etc. \\
\hline
\end{tabular}

3. Using the values in the table, plot a curve of volume on diameter. Volumes may now be read from this curve, in terms of diameter only, at a considerable saving in time over reading volumes in terms of both height and diameter from a chart or table.

\section{Reading the Alinement Chart}

A straightedge is necessary for reading the alinement chart. One made of a strip of transparent celluloid with a fine line scratched on the under side throws no shadow and makes reading accurate and rapid. The dimensions of the strip should be about $1 \times 12 \times 1 / 32$ inches. The heavier grade of celluloid used for automobile side curtains is entirely satisfactory. To construct: (see sketch below). Scribe a very fine, straight line down the middle. Remove any burr with the thumb nail, and rub India ink into the line to make it more visible. Near one end of the straightedge cut a "V" notch as shown, being careful that the inked line bisects the angle at $\mathrm{X}$ formed by the sides of the notch. Sand all corners and edges with emery paper. A needle mounted in a cork with the point exposed completes the equipment needed.

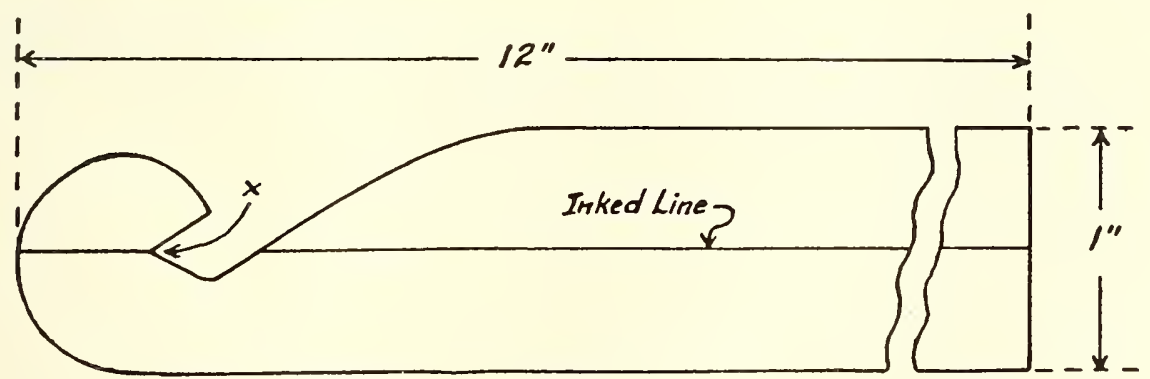

The volume of a tree of any given dimensions may be obtained from the chart by connecting its D.B.H. value on the left hand scale with its total height value on the right hand scale by a straight line, and reading volume at the intersection of this line with the middle scale. For example, to secure the volume of a tree 6.3 inches D.B.H. and 38.2 feet in total height using Chart I, the straightedge and the mounted needle, place the point of the needle on the diameter scale at 6.3 inches, hook the straightedge around the needle and, using the needle as a pivot, move the straightedge until the inked line intersects the height scale at 38.2 feet. The volume, 3.88 cubic feet, will be found at the intersection of the inked line with the volume scale. 
The long axis of the needle should always be held perpendicular to the surface of the chart and the inked line should always be on the under side of the straightedge next to the chart.

\section{Application of the Volume Tables}

As previously stated, the data for the volume tables included were secured entirely in Connecticut. If the tables are to be used in other regions, their applicability should be tested. To do this, fell 20 to 25 trees selected to give a good range of diameters and heights, and measure after the manner employed in the construction of the table. Compute the volumes of these trees by standard methods using the same units (cubic feet, board feet, cords) and the same limits of utilization as in the table. Express the deviation for each tree as a percentage of the tabular volume of a tree of the same dimensions. Compute the average of these percentage deviations for comparison with the average percentage deviation as shown in the table.

Compare the total volume of the felled trees with the total of the tabular volumes of these trees to arrive at the aggregate deviation. If the average percentage deviation of the local trees is not appreciably greater than that of the table, and if their aggregate deviation is not more than two and one-half times the average percentage deviation of the table divided by the square root of the number of trees used in the test, correction for locality is unnecessary.

If the volumes of the local trees differ consistently from the tabular values, the table should be corrected. If the table is to be used for limits of utilization other than those used in its construction, it must be corrected to give volumes in terms of the new limits ${ }^{1}$.

1 For information on the correction of volume tables for locality and for different limits of utilization the reader is referred to Miscellaneous Publication No. 50, U. S. Department of Agriculture, Washington, D. C., Volume, Yield and Stand Tables for Second-Growth Southern Pines, prepared by Office of Forest Experiment Stations, Forest Service, and Cooperating Agencies. 
D. B. H.

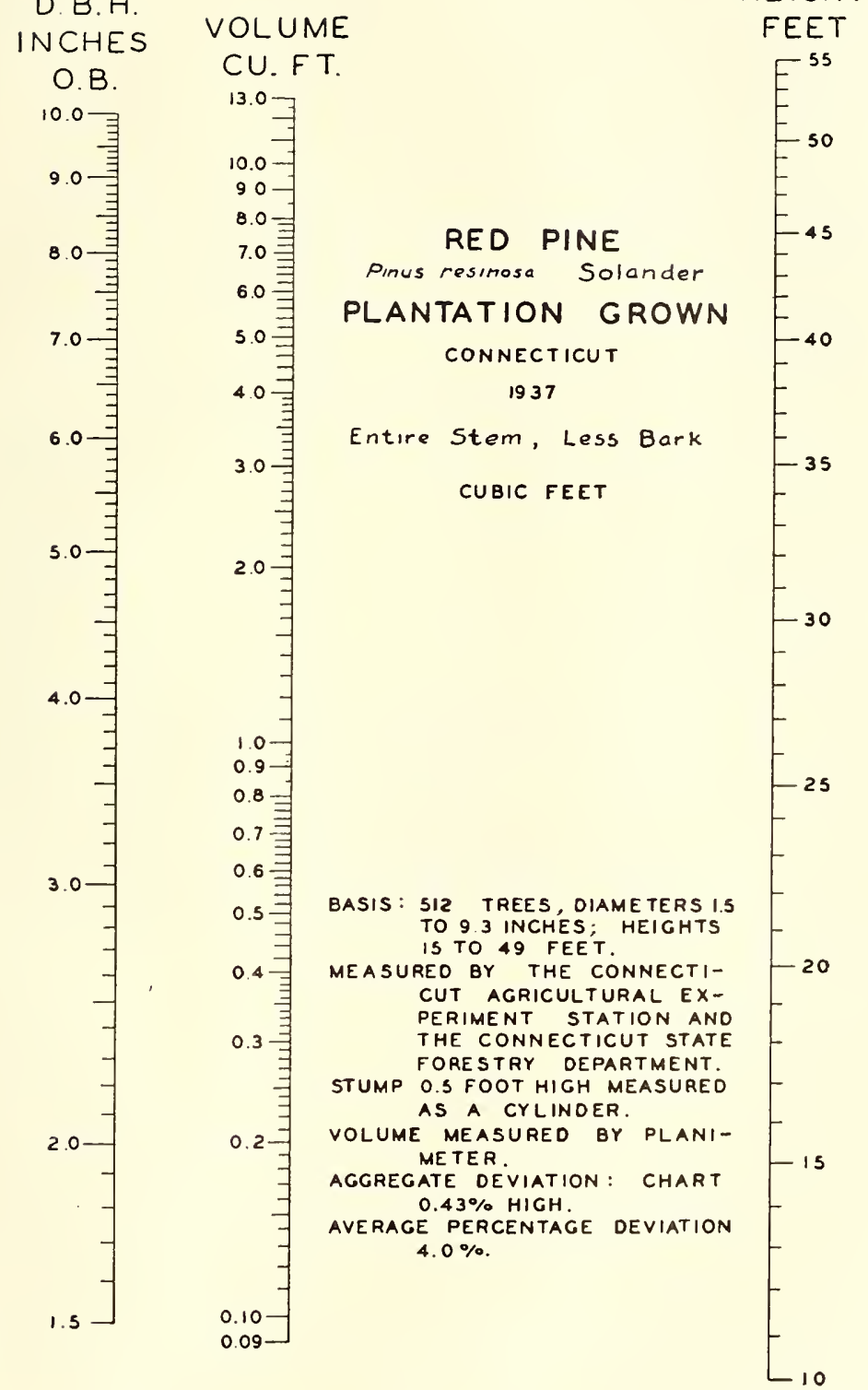

Chart I. Alinement chart for volumes of red pine showing total contents of the stem, without bark, in cubic feet. 


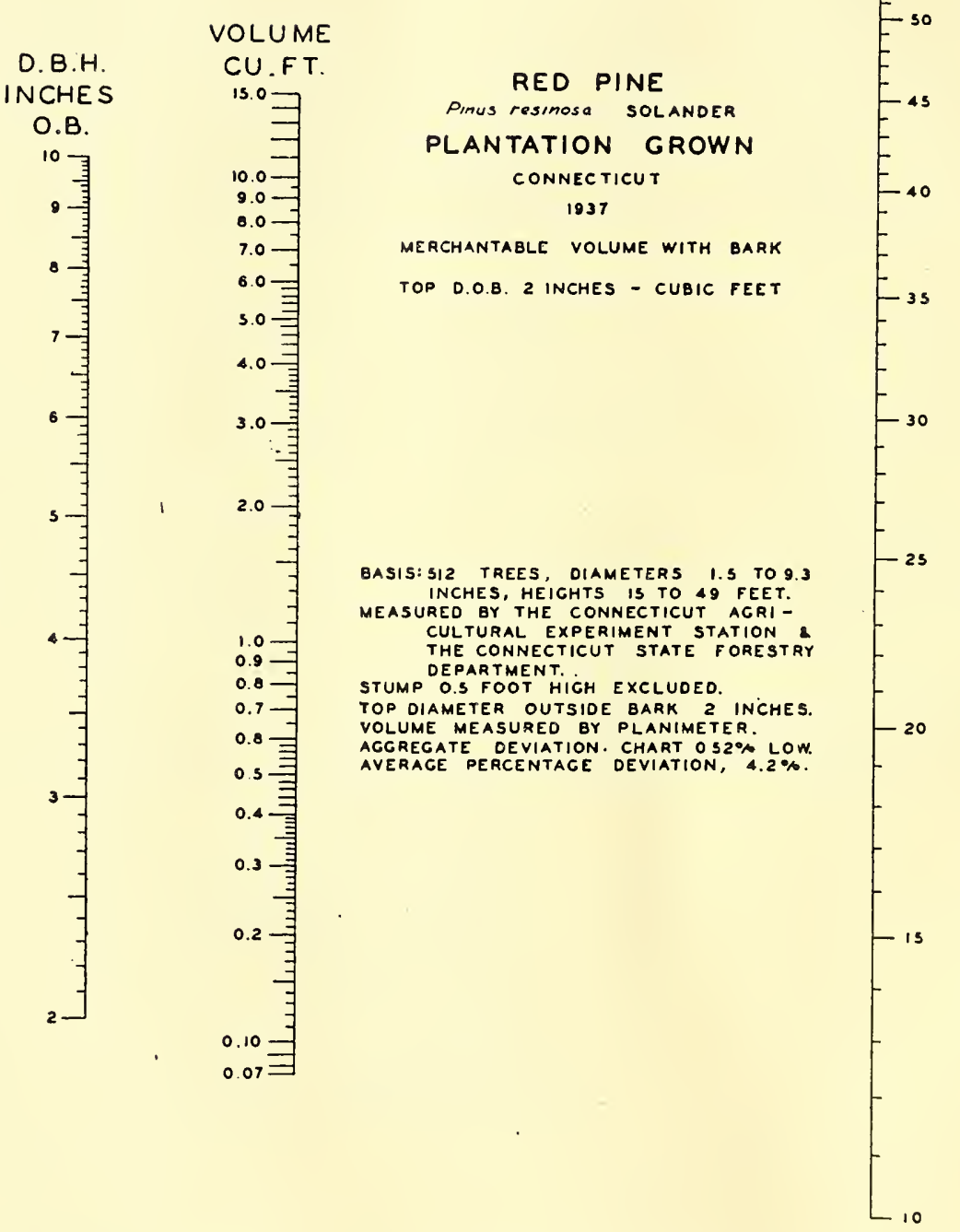

Chart II. Alinement chart for volumes of red pine showing merchantable contents of the stem, including bark, in cubic feet. 
Red Pine-Volume Tables

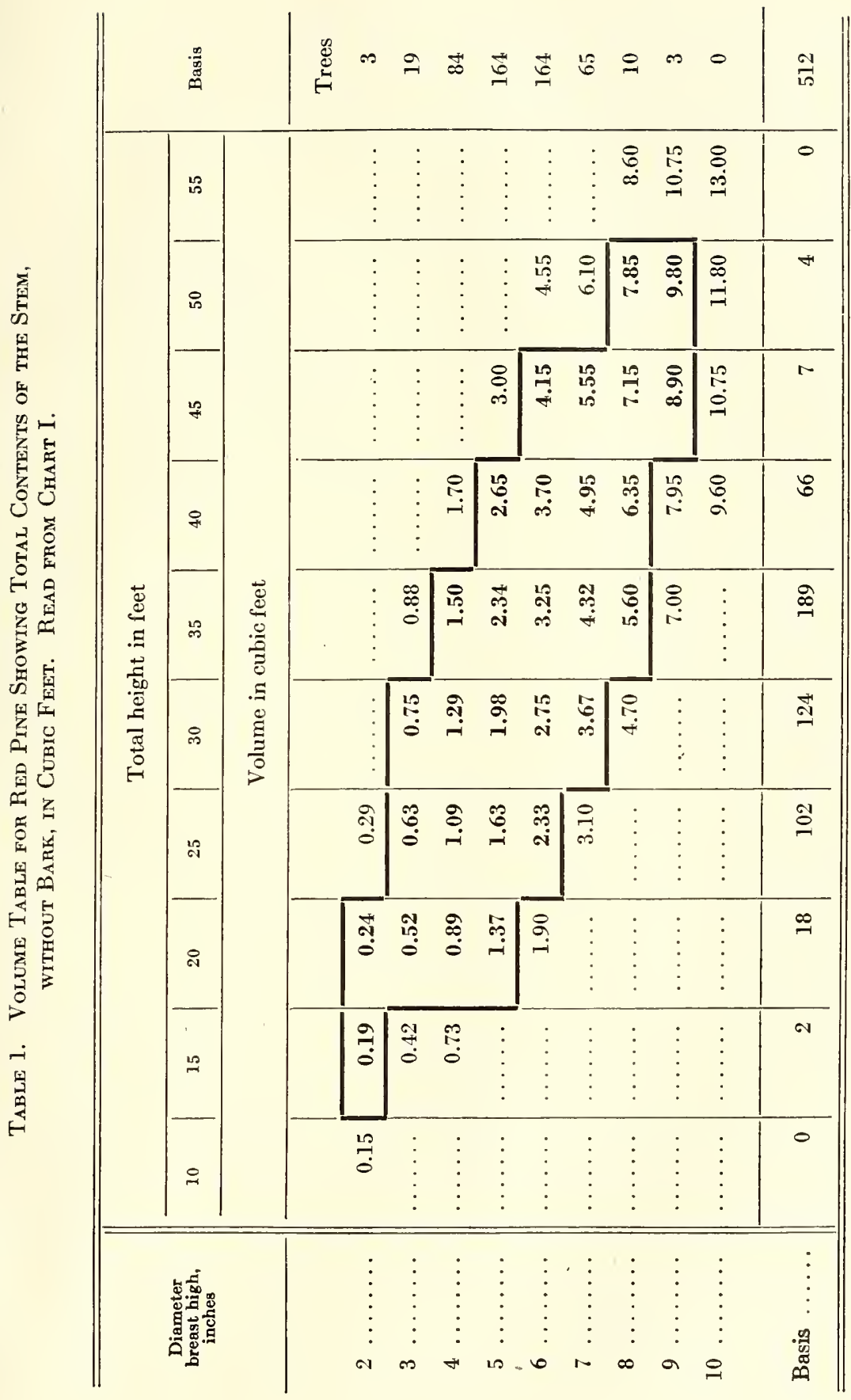




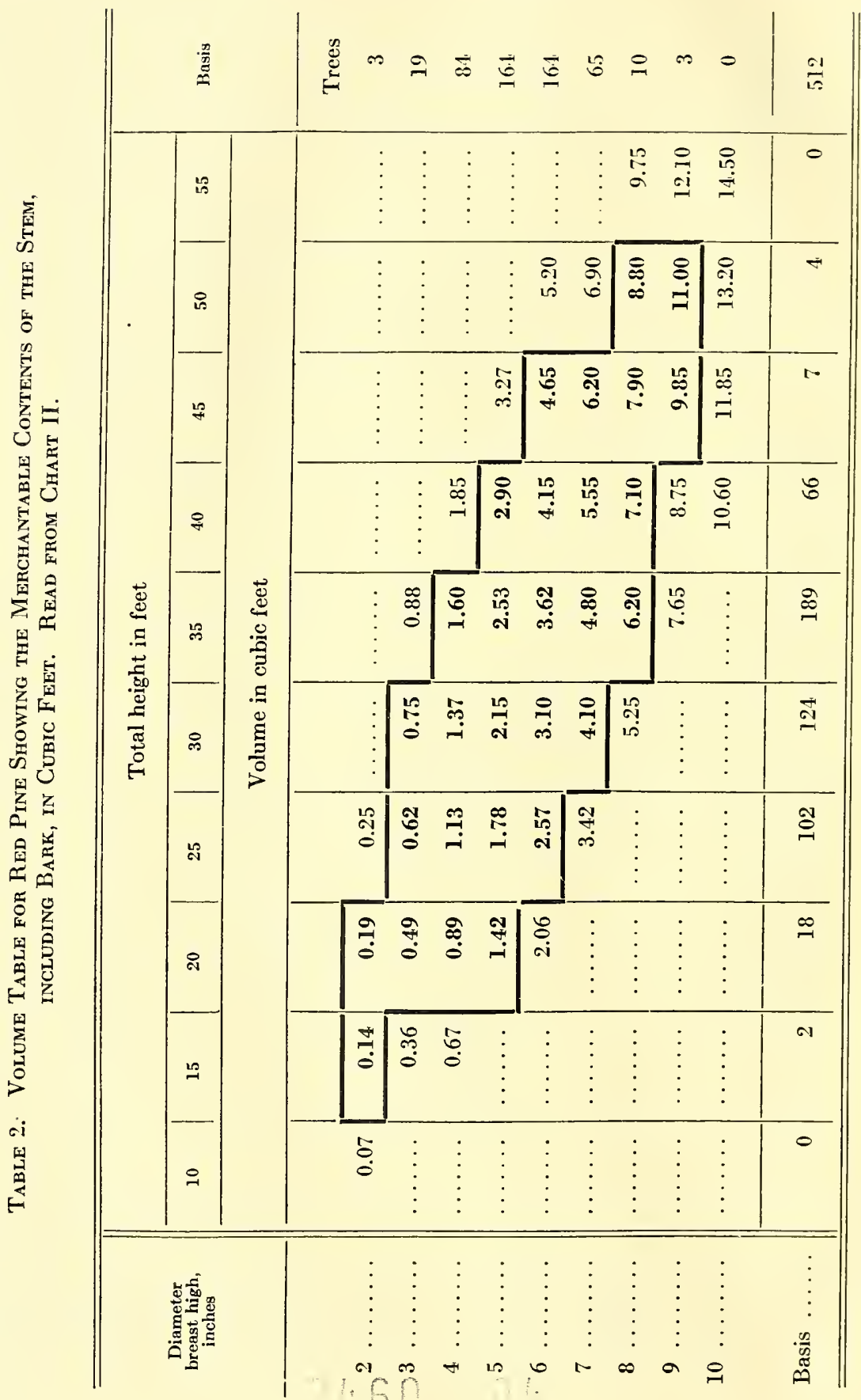






\section{University of}

Connecticut

Libraries 


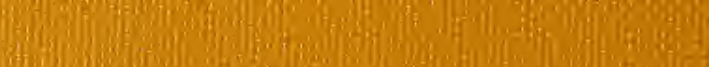

ans

and

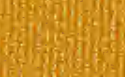

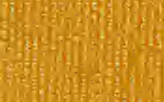

Shing $(5)$

Ining

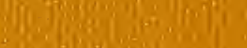

(4)

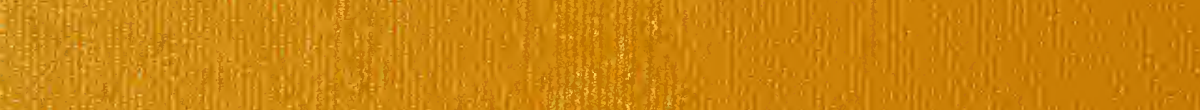

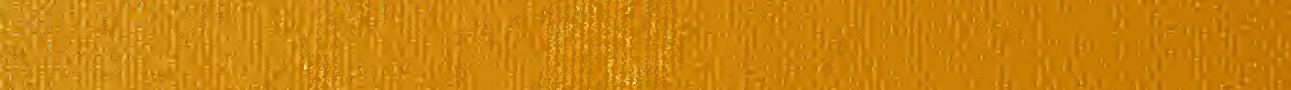
(5e)

Q

(In)

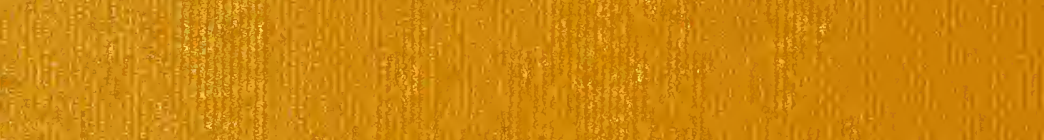

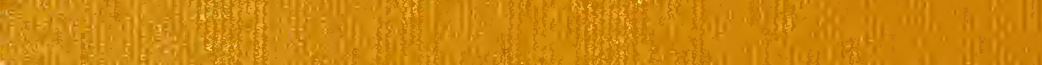

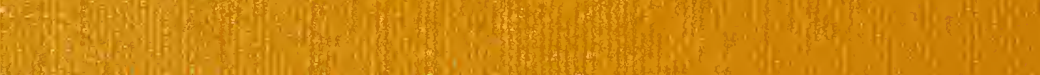

3th

He

Whe

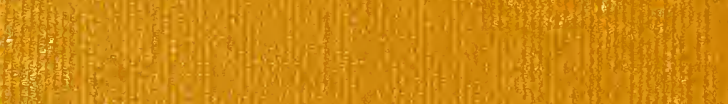

W.

W.1.0.

6.

(3)

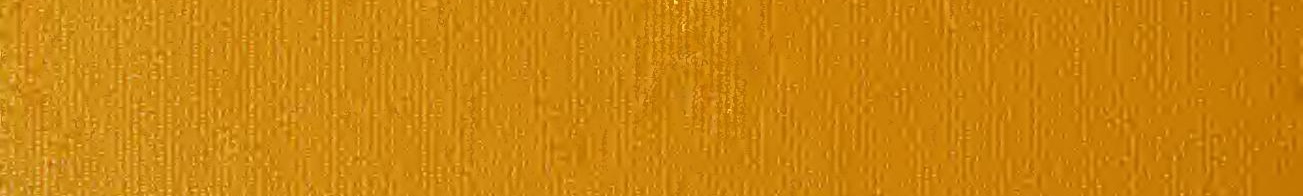

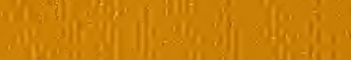

(i)

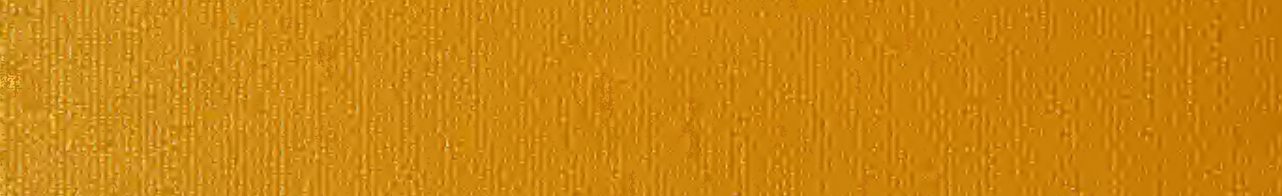

S.

(5)

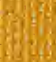

